\title{
In situ ATR - FTIR study of uranyl sorption at illite - solution interface in the presence of phosphate ions
}

\author{
MR. SHANGYAO GUO ${ }^{1}$, MIRELLA DEL NERO ${ }^{2}$, SYLVIA \\ MEYER-GEORG ${ }^{3}$, OLIVIER COURSON ${ }^{3}$ AND REMI \\ BARILLON $^{4}$ \\ ${ }^{1}$ Institut Pluridisciplinaire Hubert Curien \\ ${ }^{2}$ IPHC CNRS \\ ${ }^{3}$ Institut Pluridisciplinaire Hubert Curien, IPHC UMR 7178, \\ CNRS \\ ${ }^{4}$ IPHC \\ Presenting Author: shangyao.guo@iphc.cnrs.fr
}

Introduction: Gaining insights into mechanisms of uranyl sorption onto illite, at a realistic and low concentration of uranyl in the micromole range per liter, is highly needed for providing refined mechanistic process understanding of radionuclide retention in clay systems. Moreover, studying uranyl sorption processes due to the presence of aqueous ligands (such as phosphate) is mandatory for the transferability of experimental results on radionuclide retention to "the real system". We addressed the interactions between uranyl ions (1$10 \mu \mathrm{M})$, phosphate ions and illite surface by using batch sorption experiments and Attenuated Total Reflectance - FTIR spectroscopy.

Materials and methods: homo-ionic illite du Puy $<75 \mu \mathrm{M}$ was used as "received illite" material. Batch experiments were performed under atmospheric conditions at $\mathrm{pH} 4-8$, solid/ liquid ratio: $0.5 \mathrm{~g}-3 \mathrm{~g} / \mathrm{L}$. We monitored by ATR-FTIR spectroscopy the dynamics of phosphate species at the illitesolution interface during sorption process.

\section{Phosphate sorption}

Batch experiments showed an increasing amount of phosphate sorbed with increasing initial aqueus phosphate concentration, until reaching a plateau. Examining changes in IR spectra during phosphate sorption, for frequency regions characteristics of phosphate ions $\left(900-1200 \mathrm{~cm}^{-1}\right)$, suggested the existence of two types of sorption mechanisms. Resolving IR spectra of phosphate - illite interface showed an increase of IR bands at 1075 and $1157 \mathrm{~cm}^{-1}$, with increasing initial phosphate concentrations, as well as appearance of bands at 1009 and $1040 \mathrm{~cm}^{-1}$ at high phosphate concentrations. This suggested formation of an outer sphere surface complex of phosphate and an increasing contribution of an inner-sphere phosphate surface complex forming at high concentrations. It is hypothesized that the latter is probably a bidentate phosphate surface complex formed at aluminol / ferrinol sites present at edges of illite.

\section{Uranyl sorption}

Sorption isotherms of uranyl in the illite-solution system at $\mathrm{pH}$ 4 showed that : (1) the amount of $U$ sorbed on illite increased with the initial concentration of uranyl in experiment until reaching a plateau, and (2) the presence of phosphate ions increased the uranyl adsorption. ATR-FTIR experiments are under progress in order to gain insights into the uranyl species formed at the illite-phosphate - solution interface. 